\title{
السمات الثخصية القيادية لمدرسي التربية الرياضية من وجهة نظر إدارات المدارس المتوسطة في \\ مديريات بغداد الرصافة
}

\author{
أ.د. صالح راضي أميش \\ كلية التربية البذنية وعلوم الرياضة - جامعة بغداد \\ sali.ra@gmail.com \\ (00964) 07705077866
}

\author{
اياد طارق عزيز \\ كلية التربية البدنية وعلوم الرياضة - جامعة بغداد \\ iyad.alrubae@gmail.com
}

(00964) 07716898772

\begin{abstract}
مستخلص البحث باللغة العربية
هدف البحث الى اعداد مقياس السمات الثخصية القيادية لمدرسي التربية الرياضية من وجهة نظر إدارات المدارس بارس المتوسطة في مديريات بغداد الرصافة، والتعرف على مستوى السمات الثخصية القيادية لمدرسي التربية الرياضية من

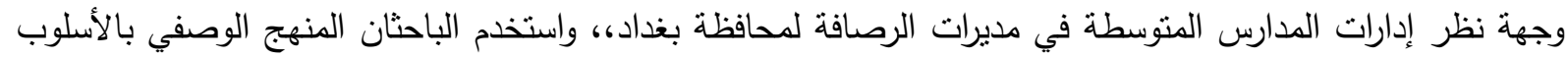
المسحي لملائمته مع طبيعة المشكلة، وتم تحديد مجتمع البحث من المدارس المتوسطة في مديريات محافظة بغداد

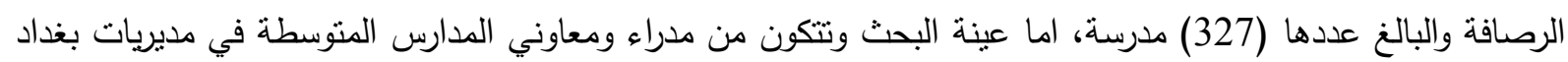
الرصافة والبالغ عددهم (420) فرداً موزعين على (130) مدرسة متوسطة، أي بنسبة (40\%) من المجتمع الأصل. واقترح الباحث (25) فقرة للمقياس وعرضها على (10) خبراء والذين وافقوا على (20) فقرة، بعد ذلك تم تطبيق المقياس على عينة البناء البالغ عددها (180) فرداً لاستخراج الأسس العلمية، بعدها تم تطبيق المقياس على عينة البحث البالغ عددها (100)

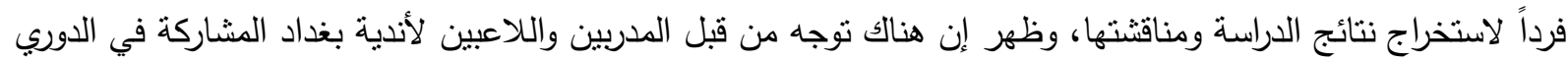
العراقي الممتاز بكرة القدم نحو الخصخصة الرياضية.

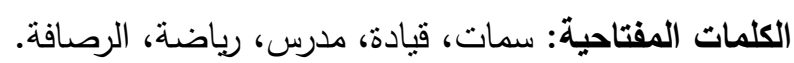

\section{ABSTRACT \\ Leadership Personality Traits of Physical Educators from Secondary School Administration Point of View In Baghdad / Al Resafa Directorates \\ Iyad Tariq Aziz \\ College of Physical Education and Sports Sciences - University of Baghdad \\ College of Physical Education and Sports Sciences - University of Baghdad}

The aim of the research is designing a leadership personality traits scale for physical educators from secondary school administration point of view in Baghdad / Al Resafa Directorates as well as identifying the level of leadership trait level for physical educators from secondary school administration point of view in Baghdad / Al Resafa Directorates. The researchers used the descriptive method on (327) secondary schools in Baghdad/ Al Rasafa directorates; the subjects were (420) principles and assistant principals of secondary schools. The researchers proposed (25) item for measurement and after being revised by experts 20 items were approved and applied on (180)construction subject followed by (100) research subjects. The results of the research show an attitude towards sport privatization in primer soccer league.

Keywords: traits, leaders, physical educators, Al Rasafa. 
اهتمت العديد من المراجع العلمية في مجال الإدارة بموضوع القيادة، إذ اصبحت القيادة بمثابة الحجر الأساس في الإدارة، والتي بعدها اتسع الاهتمام بموضوع القيادة الإدارية في مراجع علم النفس الرياضي؛ نظراً لارتباطه بكل مفاصل

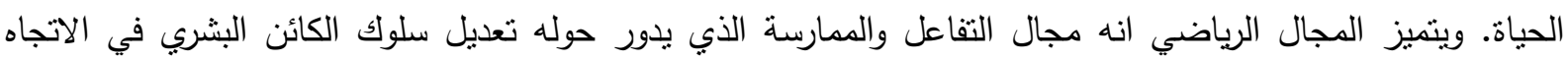
المرغوب، وخلق المواطن الصالح بوساطة تهيئة المناخ الملائم وتكوين الاتجاهات الإيجابية للافراد نحو المجتمع الذي لهي

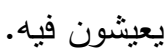
والسمات الثخصية هي احد المواضيع التي اهتم بها العلماء؛ لأنها تتتاول الفرد في كل جوانبه النفسية ومفرداته البدنية والعقلية وما يتعلق به من أنثطة متتوعة تؤثر علية من تفاعله مع محبطة، وركز الباحثون على السمة؛ إذ اعتبروها

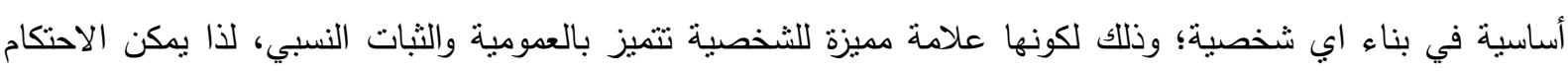
اليها في تقويم الثخصية والتمييز بين الافراد وتصف الانسان بناء على ما يصدر عنه من سلوك في المواقف المختلفة. ونحن نحتاج إلى مدرسين بتمتعون بسمة الثخصية القيادية المؤثرة، والثخصية القيادية للمربي تمثل السلاح

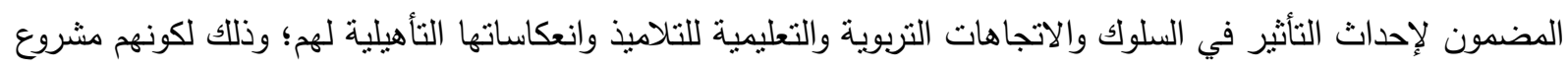
مستقبلي في اعدادهم كقادة في المجتمع. وإن السمات الثخصية القيادية المطلوب توافرها في المدرس تعتمد على منطلبات المواقف الذي يمارس فيه قيادته، على سبيل المثال ان مدرس التربية الرياضية يحتاج سمات غير السمات التي يحتاجها مدير المصنع، وسمات القائد العسكري غير سمات القائد التربوي، وهكذا، إذ ان هذا لا ينفي وجود بعض السمات الأساسية المشتركة بين منطلبات المواقف والمنظمات المختلفة. ونظراً لأهمية القيادة وسماتها وللدور الذي تؤديه في الددارس، جاءت هذه الدراسة للتعرف على نوافر السمات

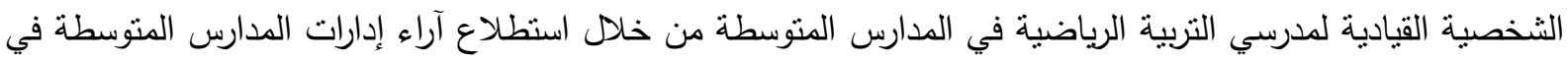
مديريات بغداد الرصافة.

وإن التعرف على السمات الثخصية القيادية ودراستها وتحليلها يكتسب أهمية منميزة في تصنيف المدرسين ضمن

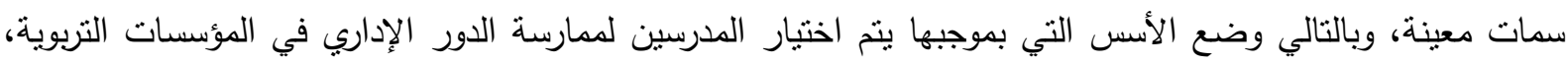

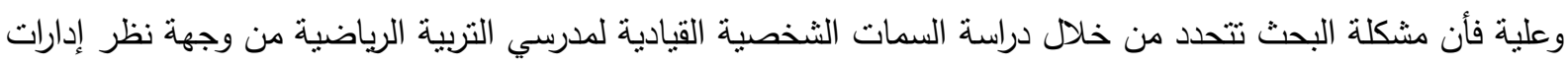
المدارس المتوسطة في مديريات بغداد الرصافة. ويذكر (جلاب، 2011) في دراسة استخدم فيها المنهج الوصفي بالأسلوب المسحي على عينة من (155) فرداً توصل فيها الى الاهتمام بالبرامج التي من شأنها ان تطور السمات الثخصية للقادة الكثفيين من حملة الثارة الخشبية. اما في دراسة (موسى وعبد الواحد، 2013) والتي استخدما فيها المنهج الوصفي على عينة من (200) فرداً فتوصل فيها إلى ان الفرد الذي لديه مستوى جيد من سمات الثخصية لا بد له أن يمتلك قدرة جيدة على حل المشاكل وهذا ما أثنتته النتائج، وان التلميذ الذي لايهر سمات شخصية جيدة يكون أفضل من التلميذ الذي لديهر سمات شخصية ضعيفة في حل المشكلات. وفي دراسة (عبد السادة، 2014) والتي استخدم فيها المنهج الوصفي بالأسلوب المسحي، على عينة من (110) فرداً، فتوصل فيها إلى ظهور علاقة ارتباط بين الشخصية القيادية والكفاءة المهنية، وان للشخصية القيادية أهمية في مستوى الكفاءة المهنية لدى مدرسي الجامعة، وان الثخصية القيادية للأستاذة الجامعيين لها تأثنير كبير على العملية التدريسية والتزبوية. 
ومن هنا يظهر الهدف من البحث وهو اعداد مقياس السمات الثخصية القيادية لمدرسي التربية الرياضية من وجهة

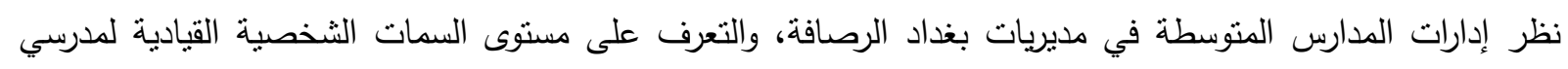

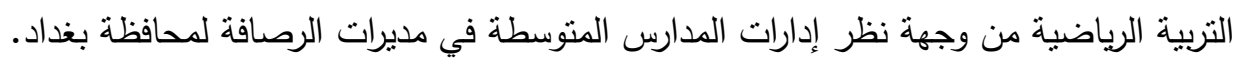

\section{الطريقة والأدوات:}

استخدم الباحثان المنهج الوصفي بالأسلوب المسحي لملائمته مع طبيعة المشكلة. وتم تحديد مجتمع البحث من المدارس المتوسطة في مديريات محافظة بغداد الرصافة والبالغ عددها (327) مدرسة، اما عينة البحث وتتكون من مدراء ومعاوني المدارس المتوسطة في مديريات بغداد الرصافة والبالغ عددهم (420) فرداً موزعين على (130) مدرسة منوسطة، أي بنسبة (40\%) من المجتمع الأصل وقد نم اختيارهم بالطريقة العدية، كما

موضح في جدول (1).

\begin{tabular}{|c|c|c|c|c|c|c|c|}
\hline \multirow{2}{*}{ المستبعدين } & \multirow{2}{*}{ التطبيق } & \multirow{2}{*}{ البناء } & \multirow{2}{*}{ الاستطلاعية التجربة } & \multirow{2}{*}{ البحثة } & \multicolumn{2}{|c|}{ مجتمع البحث } & \multirow{2}{*}{ المديريات } \\
\hline & & & & & عدد الإدارات & عدد المدارس & \\
\hline 17 & 50 & 55 & 7 & 125 & 312 & 103 & الرصافة الأولى \\
\hline 21 & 73 & 80 & 8 & 183 & 457 & 141 & الرصافة الثانية \\
\hline 14 & 43 & 47 & 5 & 112 & 281 & 83 & الرصافة الثالثة \\
\hline 52 & 166 & 182 & 20 & 420 & 1050 & 327 & المجموع \\
\hline$\% 12.3$ & $\% 39.5$ & $\% 43.3$ & $\% 4.7$ & $\% 40$ & \multicolumn{2}{|c|}{$\% 100$} & النسبة المئوية \\
\hline
\end{tabular}

ولغرض تحقيق هدف البحث فأن ذلك يتطلب استبانة للقياس، لذا عمل الباحثان إلى إعداد استبانة للتعرف

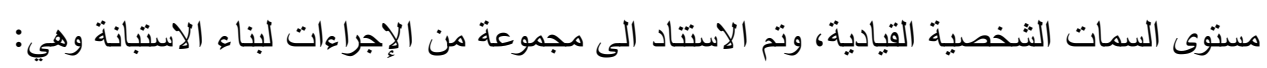

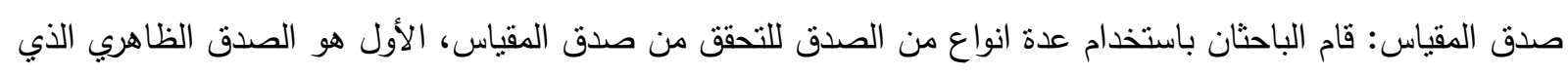
يعتد على عرض عبارات المقياس على مجموعة من الخبراء والمختصين لتقدير مدى صلاحيتها في قياس الظاهرة المراد قياسها، وقد تحقق الصدق الظاهري في مقياس هذه الدراسة من خلال عرض فقرات المقياس على مجموعة من الخبراء

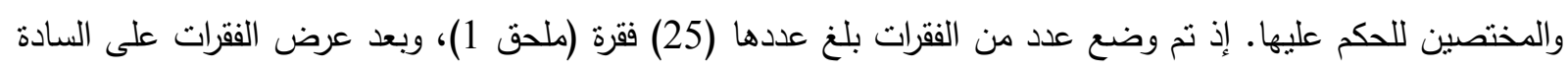

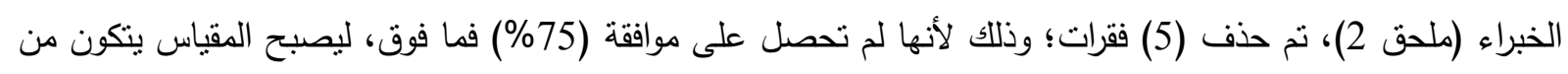

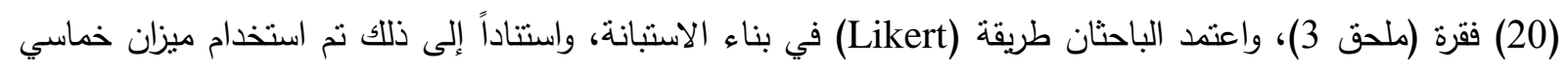

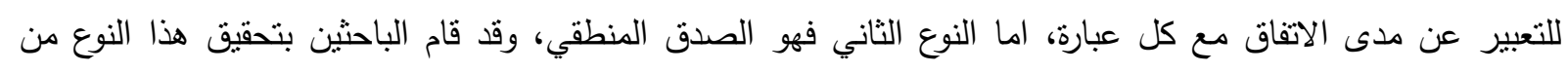

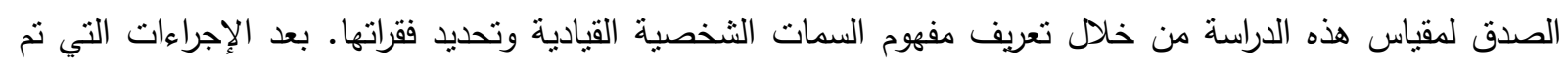
ذكرها، قام الباحثان بأجراء التجربة الاسنطلاعية على عينة من (20) فرداء لدرا، للمدة (2019/9/2) ولغاية (2019/9/10).

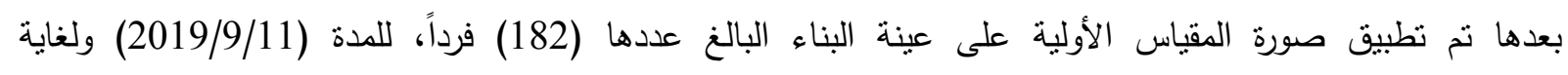

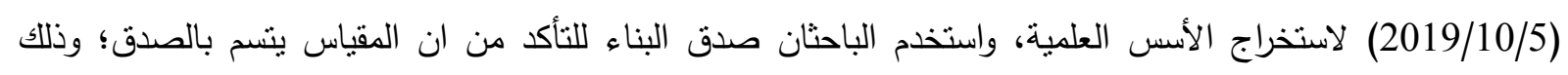

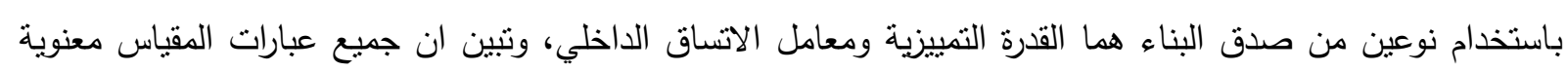

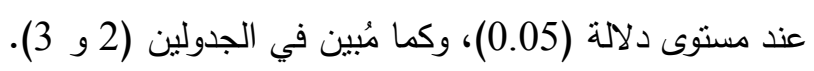


مجلة كلية التربية الرياضية / جامعة بغداد * المجلد الحادي والثلاثون * العدد الرابع * 2019.

جدول (2) يُيين القدرة التميزية لعبارات المقياس بين المجموعتين العُليا والدُنبا

\begin{tabular}{|c|c|c|c|c|c|c|c|}
\hline \multirow{2}{*}{ الإحصائية } & \multirow{2}{*}{ الحقيقية } & \multirow{2}{*}{ قالمحسوبة (T) } & \multicolumn{2}{|c|}{ المجموعة العُليا } & \multicolumn{2}{|c|}{ المجموعة الدُنيا } & \multirow{2}{*}{ العبارة } \\
\hline & & & $\varepsilon$ & س & $\varepsilon$ & س & \\
\hline معنوي & 0.000 & 35.4 & .00000 & 5.0000 & .65 & 1.693 & 1 \\
\hline معنوي & 0.000 & 27.6 & .00000 & 5.0000 & .799 & 1.836 & 2 \\
\hline معنوي & 0.000 & 20.1 & .00000 & 5.0000 & 0.841 & 2.571 & 3 \\
\hline معنوي & 0.000 & 25.0 & .00000 & 5.0000 & 0.730 & 2.387 & 4 \\
\hline معنوي & 0.000 & 27.0 & .00000 & 5.0000 & 0.649 & 2.489 & 5 \\
\hline معنوي & 0.000 & 23.2 & .00000 & 5.0000 & 0.871 & 2.102 & 6 \\
\hline معنوي & 0.000 & 26.1 & .00000 & 5.0000 & 0.763 & 2.142 & 7 \\
\hline معنوي & 0.000 & 28.6 & .00000 & 5.0408 & 0.705 & 2.040 & 8 \\
\hline معنوي & 0.000 & 23.3 & .00000 & 5.0000 & 0.765 & 2.449 & 9 \\
\hline معنوي & 0.000 & 32.5 & .00000 & 5.0000 & 0.543 & 2.469 & 10 \\
\hline معنوي & 0.000 & 26.0 & .00000 & 5.0000 & 0.635 & 2.632 & 11 \\
\hline معنوي & 0.000 & 26.2 & .00000 & 5.0000 & 0.642 & 2.591 & 12 \\
\hline معنوي & 0.000 & 27.0 & .00000 & 5.0000 & 0.649 & 2.489 & 13 \\
\hline معنوي & 0.000 & 22.7 & .00000 & 5.0000 & 0.808 & 2.367 & 14 \\
\hline معنوب & 0.000 & 33.7 & .00000 & 5.0000 & 0.536 & 2.408 & 15 \\
\hline معنوي & 0.000 & 26.5 & .00000 & 5.0000 & 0.763 & 2.000 & 16 \\
\hline معنوب & 0.000 & 27.1 & .00000 & 5.0000 & 0.688 & 2.326 & 17 \\
\hline معنوي & 0.000 & 30.7 . & .00000 & 5.0000 & 0.633 & 2.326 & 18 \\
\hline معنوي & 0.000 & 24.3 & .00000 & 5.0000 & 0.784 & 2.265 & 19 \\
\hline معنوي & 0.000 & 22.5 & .00000 & 5.0000 & 0.811 & 2.387 & 20 \\
\hline
\end{tabular}

مغنوي $\geq(0.05)$

جدول (3) يُيين معاملات الارتباط بين عبارات المقياس بالدرجة الكلية للمقياس باستعمال طريقة الاتساق الداخلي

\begin{tabular}{|c|c|c|c|c|c|c|c|}
\hline الدلالة & الحقيقية & الارتباط & العبارة & الدلالة & الحقيقية & الارتباط & رقم \\
\hline معنوي & 0.000 & 0.259 & 11 & معنوي & 0.000 & 0.301 & 1 \\
\hline معنوي & 0.001 & 0.237 & 12 & معنوي & 0.000 & 0.440 & 2 \\
\hline معنوي & 0.002 & 0.286 & 13 & معنوي & 0.000 & 0.396 & 3 \\
\hline معنوي & 0.000 & 0.412 & 14 & معنوي & 0.000 & 0.446 & 4 \\
\hline معنوي & 0.030 & 0.161 & 15 & معنوي & 0.000 & 0.406 & 5 \\
\hline معنوي & 0.000 & 0.325 & 16 & معنوي & 0.000 & 0.452 & 6 \\
\hline
\end{tabular}


مجلة كلية التربية الرياضية / جامعة بغداد ** المجلد الحادي والثلاثون* العدد الرابع * 2019.

\begin{tabular}{|c|c|c|c|c|c|c|c|}
\hline معنوي & 0.001 & 0.011 & 17 & معنوي & 0.000 & 0.404 & 7 \\
\hline معنوبي & 0.000 & 0.399 & 18 & معنوي & 0.000 & 0.256 & 8 \\
\hline معنوي & 0.000 & 0.380 & 19 & معنوي & 0.001 & 0.255 & 9 \\
\hline معنوي & 0.000 & 0.303 & 20 & معنوي & 0.000 & 0.358 & 10 \\
\hline
\end{tabular}

(0.05) معنوي

ثنات المقياس: قام الباحثان باستخدام نوعين من الثبات للتحقق من ثبات المقياس، الأول معامل الفاكرونباخ وتبين عند تطبيق هذا المعامل، أنّ معامل الثبات هو (0.699)، وتُعد قيمة عالية للثبات عند مستوى دلالة (0.05). بعد الإجراءات التي تم ذكرها قام الباحثان مع فريق العمل المساعد بتطبيق المقياس (ملحق 3) على عينة البحث والبالغ عددها (166) فرد وذلك للمدة من (2019/10/10) ولغاية (2019/10/30).

الأنتائج:

جدول (4) يُيين عرض البيانات الإحصائية لمواصفات عينة البحث

\begin{tabular}{|c|c|c|c|c|c|}
\hline أعلى درجة & أدنى درجة & معامل الالتواء & الانحراف المعياري & الوسط الحسابي & المقياس \\
\hline 92 & 42 & $0.467-$ & 8.733 & 75.192 & السمات الثخصية \\
\hline
\end{tabular}

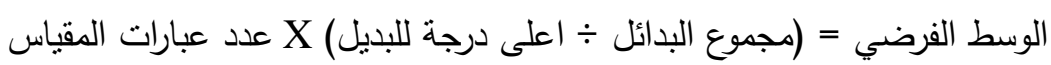

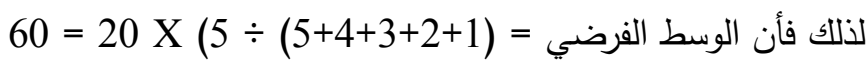
جدول (5) يُيين الوسط الحسابي والوسط الفرضي والانحراف المعياري وقيمة (T) المحسوبة والمعنوية الحقيقية ونوع الفرق لمقياس البحث

\begin{tabular}{|c|c|c|c|c|c|}
\hline نوع الفرق & قيمة الدلالة & قالمحسة (T) & الانحراف & الوسط الحسابي & المتغيرات \\
\hline معنوي & 0.000 & 11.413 & 8.733 & 75.192 & السمات الثخصية القيادية \\
\hline \multicolumn{3}{|c|}{60} & \multicolumn{3}{|c|}{ الوســـــــ الفرضــــــــي } \\
\hline
\end{tabular}

منوي $\geq 0.05$ عند درجة حرية (165).

\section{المناقشة:}

يتبين من خلال الجدول (4) ان الوسط الحسابي لمواصفات عينة البحث كان (75.195) وبانحراف معياري (8.733) ومعامل التواء كان (-0.467) وهو بين (1+) مما يظهر ان مواصفات هي مناسبة للقيام بالبحث. وبوساطة عرض وتحليل ومناقثة النتائج توصل الباحثان إلى ان هناللك سمات شخصية قيادية لدى مدرسي التربية الرياضية في محافظة بغداد/ الرصافة. وان الثخصية القيادية لمدرسي التربية الرياضية مؤثرة بصورة كبيرة على العملية التدريسية والتربوية. ويتبين من خلال الجدول (5) إن الثخصية القيادية للمدرسين تعد الوسيلة المضمونة لإحداث التغيير والتأثنير في

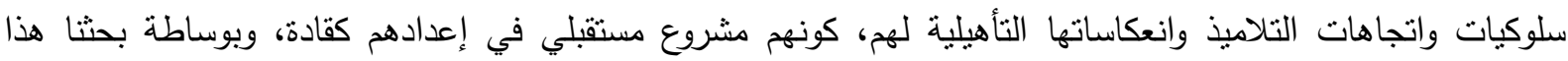
استتنجنا أن المدرسين كلما كانوا يتحلون بسمة الثخصية القيادية كلما استطاعوا ان يقودوا العملية التدريسية والتربوية 
بنجاح "مما يؤدي إلى إيصال أكبر قدر ممكن من العلم والمعرفة الأكاديمية والاجتماعية لدى التلاميذ الذين هم النواة

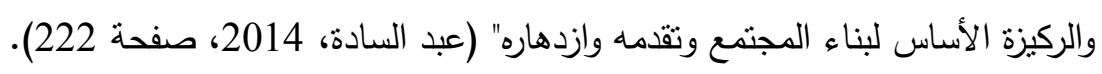

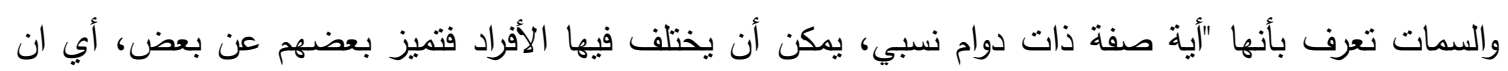

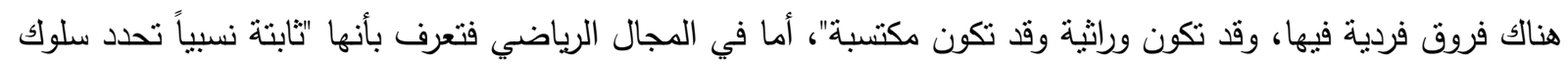

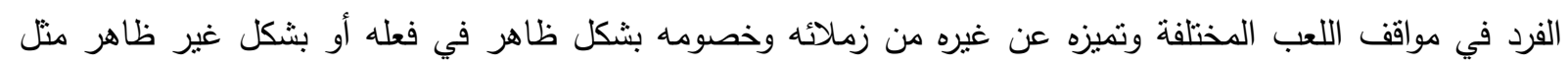

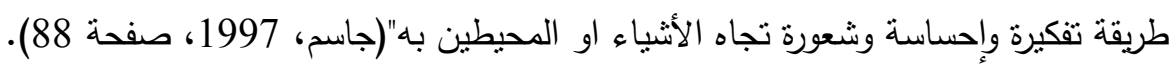

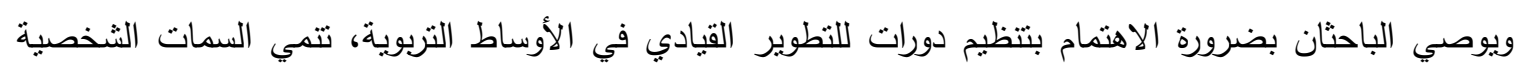

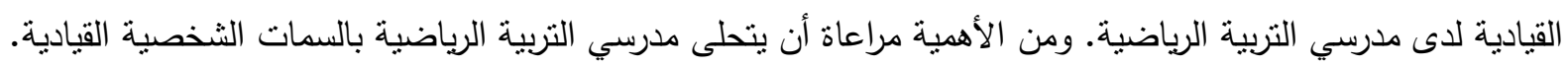

\section{المصادر}

سليم حسن جلاب (2011). بناء مقياس لبعض السمات الثخصية القيادية لحملة الثارة الخشبية الكثفية في العراق. مجلة جامعة الانبار للعلوم الرياضية. المجلد 1. عامر سعيد جاسم، (1997) السمات الثخصية وعلاقتها بمسنوى الانجاز للاعبي المبارزة، (رسالة ماجستير، كلية التربية الرياضية، جامعة بغداد. غسان محمد عبد السادة (2014). الثخصية القيادية للأستاذ الجامعي وعلاقتها بمستوى كفاءته المهنية من وجهة نظر طلبتها. جامعة الكوفة. كلية التربية الرياضية. مجلة علوم التربية الرياضية. المجلد 7. العدد 2.

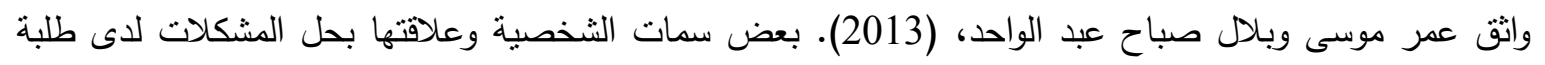

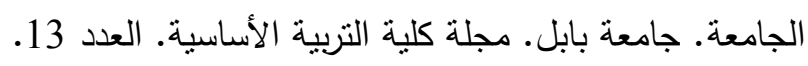


ملحق (1)

استبانة آراء الخبراء والمختصين حول صلاحية فقرات المقياس

.المحترم. الأستاذ الفاضل.

تحية طيبة: بعد التوكل على الله يروم الباحث إجراء بحثه الموسوم (السمات الثخصية القيادية لمدرسي التربية الرياضية من وجهة نظر إدارات

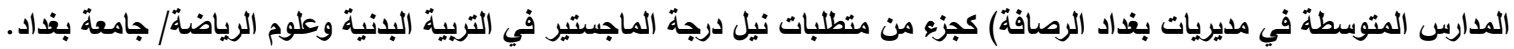
ونظراً لما تتمتعون به من خبرة وعلم فأن الباحث يأمل منكم المساعدة في بناء المقياس من خلال إبداء الرأي في صلاحية فقرات المقياس.

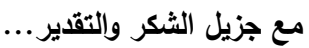

التوقيع:

مكان العمل:

الاختصاص:

الاسم واللقب العلمي:

المقياس بصورته الاولية

\begin{tabular}{|c|c|c|c|c|}
\hline الملاحظات & لا تصلح & تصلح & 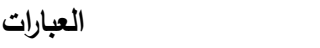 & $ت$ \\
\hline & & & المهابة & 1 \\
\hline & & & لا يتأثر بالنقد الموجة الية & 2 \\
\hline & & & تفويض المسؤولية & 3 \\
\hline & & & يستطيع تحمل المسؤولية & 4 \\
\hline & & & قادر على فهم الآخرين & 5 \\
\hline & & & قدوة حسنة & 6 \\
\hline & & & لدية القدرة على الاقناع & 7 \\
\hline & & & قوة التحمل & 8 \\
\hline & & & الأمانة & 9 \\
\hline & & & النزاهة & 10 \\
\hline & & & الالتزام & 11 \\
\hline & & & العدالة والمساواة & 12 \\
\hline & & & المهنية & 13 \\
\hline & & & الحكمة & 14 \\
\hline & & & الانضباط & 15 \\
\hline & & & لبق بالكلام & 16 \\
\hline & & & يتقبل الآراء & 17 \\
\hline & & & قيادي & 18 \\
\hline & & & سرعة البديهة & 19 \\
\hline & & & الحيوية والنشاط & 20 \\
\hline & & & الابتكار & 21 \\
\hline & & & يظهر الثقة للطلبة & 22 \\
\hline & & & جدي في العمل & 23 \\
\hline & & & 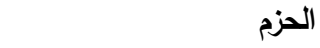 & 24 \\
\hline & & & ضبط النفس & 25 \\
\hline
\end{tabular}


مجلة كلية التربية الرياضية / جامعة بغداد * المجلد الحادي والثلاثون * العدد الرابع * 2019. ملحق (2) يُيين أسماء الخبراء والمختصين لتحديد صلاحية فقرات المقياس

\begin{tabular}{|c|c|c|c|}
\hline مكان العمل & الاختصاص & 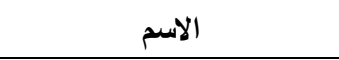 & $ت$ \\
\hline كلية التربية البدنية وعلوم الرياضة/ جامعة بذاد & الإدارة والتنظيم & أ.د عبد الله هزاع الثافعي & 1 \\
\hline كلية التربية البدنية وعلوم الرياضة/ جامعة بذاد & علم النفس & أ.د علي يوسف حسين & 2 \\
\hline كلية التربية البدنية وعلوم الرياضة/ جامعة بغداد & الاختبارات والقياس & أ. أد رياض خليل خماس & 3 \\
\hline كلية التربية البدنية وعلوم الرياضة/ جامعة بغداد & اختبارات وتقويم & أ.د زهرة شهاب أحمد & 4 \\
\hline كلية التربية البدنية وعلوم الرياضة/ جامعة بغداد & اختبار وقياس & أ.د عباس علي عذاب & 5 \\
\hline كلية التربية البننية وعلوم الرياضة/ جامعة بغداد & علم النفس & أ.م.د وفاء صباح محمد & 6 \\
\hline كلية التربية البدنية وعلوم الرياضة/ جامعة بذاد & الاختبارات والقياس & أ.د فارس سامي يوسف شيعا & 7 \\
\hline كلية التربية البدنية وعلوم الرياضة/ جامعة بغاد & الإدارة والتنظيم & أ.د.م صلاح وهاب شاكر & 8 \\
\hline كلية التربية البدنية وعلوم الرياضة/ جامعة بغداد & اختبارات وقياس & أ.م.د طارق علي يوسف & 9 \\
\hline كلية التربية البدنية وعلوم الرياضة/ جامعة بغداد & علم النفس الرياضي & أ.م.د نداء ياسر & 10 \\
\hline
\end{tabular}

ملحق (3) المقياس المعدل بصورته النهائية

\begin{tabular}{|c|c|c|c|c|c|c|}
\hline \multicolumn{5}{|c|}{ تتوافر في المدرس بدرجة } & \multirow{2}{*}{ الفقرات } & \\
\hline كبيرة جداً & قليلة & كبيرة جداً & كبيرة & كبيرة جداً & & \\
\hline & & & & & المهابة & 1 \\
\hline & & & & & لا يتأثر بالنق الموجة الية & 2 \\
\hline & & & & & تفويض المسؤولية & 3 \\
\hline & & & & & يستطيع تحمل المسوؤية & 4 \\
\hline & & & & & جدي في العمل & 5 \\
\hline & & & & & قلقوة حسنة & 6 \\
\hline & & & & & لاية القدرة على الاقتاع & 7 \\
\hline & & & & & الحزم & 8 \\
\hline & & & & & الأمانة & 9 \\
\hline & & & & & النزاهة & 10 \\
\hline & & & & & الالتزام & 11 \\
\hline & & & & & العدالة والمساواة & 12 \\
\hline & & & & & المهنية & 13 \\
\hline & & & & & 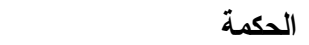 & 14 \\
\hline & & & & & الانضباط & 15 \\
\hline & & & & & الابتكار & 16 \\
\hline & & & & & يظهر الثقة للطبة & 17 \\
\hline & & & & & ق قيادي & 18 \\
\hline & & & & & سرعة البديهة & 19 \\
\hline & & & & & الحيوية والنشاط & 20 \\
\hline
\end{tabular}

